\title{
sciendo
}

\section{Primary hypothyroidism and autoimmune thyroiditis alter the transcriptional activity of genes regulating neurogenesis in the blood of patients}

\author{
Iryna I. Bilous ${ }^{1}$, Larysa L. PAVlovyCH ${ }^{2}$, Aleksandr M. KAMyshny I ${ }^{3}$ \\ ${ }^{1}$ Department of Medical Rehabilitation, I. Horbachevsky Ternopil National Medical University, Ternopil, Ukraine; \\ 2Department of Clinical Immunology, Allergology and Endocrinology, HSEEU "Bukovinian State Medical University", \\ Chernivtsi, Ukraine; ${ }^{3}$ Department of Microbiology, Virology, and Immunology, I. Horbachevsky Ternopil National \\ Medical University, Ternopil, Ukraine \\ E-mail:Iryna.bilous2017@gmail.com
}

\begin{abstract}
Objective. Thyroid hormones play an important role in the development and maturation of the central nervous symptom and their failure in the prenatal period leading to an irreversible brain damage. Their effect on the brain of adult, however, has not been fully studied. With the discovery of neurogenesis in the adult brain, many recent studies have been focused on the understanding the basic mechanisms controlling this process. Many neurogenesis regulatory genes are not only transcribed but also translated into the blood cells. The goal of our study was to analyze the transcriptional activity of neurogenesis regulatory genes in peripheral blood cells in patients with thyroid pathology.

Methods. The pathway-specific PCR array (Neurotrophins and Receptors RT2 Profiler PCR Array, QIAGEN, Germany) was used to identify and validate the neurogenesis regulatory genes expression in patients with thyroid pathology and control group.

Results. The results showed that GFRA3, NGFR, NRG1, NTF3, NTRK1, and NTRK2 significantly decreased their expression in patients with autoimmune thyroiditis with rising serum of autoantibodies. The patients with primary hypothyroidism, as a result of autoimmune thyroiditis and postoperative hypothyroidism, had significantly lower expression of FGF2, NGFR, NRG1, and NTF3. The mRNA level of CNTFR was markedly decreased in the group of patients with postoperative hypothyroidism. No change in the ARTN, PSPN, TFG, MT3, and NELL1 expression was observed in any group of patients.

Conclusion. The finding indicates that a decrease in thyroid hormones and a high level of autoantibodies, such as anti-thyroglobulin antibody and anti-thyroid peroxidase antibody, affect the expression of mRNA neurogenesis-regulated genes in patients with thyroid pathology.
\end{abstract}

Key words: neurogenesis, mRNA, autoimmune thyroiditis, hypothyroidism

Thyroid hormones have a significant effect on the brain and neuropsychiatric dysfunction and are often found in hypothyroidism (Feldman et al. 2013; Samuels 2014). Cognitive and affective impairments are often present in the hypothyroidism (Samuels 2014). On the other hand, autoimmune thyroiditis (AIT) is associated with depression and anxiety disor- ders (Siegmann et al. 2018). In patients with hypothyroidism decrease in the volume of the hippocampus has been observed and confirmed by imaging studies (Cooke et al. 2014).

Thyroid hormone plays a vital role during the shaping and development of the nervous system in mammals (Rovet 2014). A few prospective studies

Corresponding author: Iryna I. Bilous, M.D., PhD., Department of Medical Rehabilitation, I. Horbachevsky Ternopil National Medical University; Majdan Voli 1, 46001 Ternopil, Ukraine; phone: +380954313068; e-mail: Iryna.bilous2017@gmail.com. 
have underscored the significant role of the thyroid hormone within the adult brain (Schroeder and Privalsky 2014). The effect of thyroid hormone on the adult mammalian brain is a subject of regulation at different levels. These are related to changes in the local availability of thyroid hormone through the regulation of the transport and the enzymatic activity of different types of deiodinases, differential expression of TR isoforms, interaction of TRs with corepressor or coactivator complexes, balance of ligand-dependent and independent changes in gene expression, in addition to the nongenomic actions of thyroid hormone. Nevertheless, the regulatory mechanisms of the effect of the endocrine pathology of the thyroid gland on the functioning of the nervous system have insufficiently been studied.

We have earlier demonstrated that AIT and hypothyroidism can affect the expression of mRNA nerve impulse transmission genes in a gene-specific manner. These changes in gene expressions can also play an important role in the development of neurological complications related to thyroid pathology (Bilous et al. 2020a, b). Nevertheless, neurogenesis is a remarkable form of brain structural plasticity, by which new functional neurons are generated from adult neural stem cells being important for learning and mood and memory regulation, whereas it is affected in disease conditions associated with cognitive impairment, depression, and anxiety (Costa et al. 2015). With the discovery of neurogenesis in the adult brain, many recent studies have been focused on the understanding of the basic mechanisms controlling this process. Neurogenesis is tightly regulated by several endogenous signaling molecules including hormones and growth factors (Costa et al. 2015). Several neurotrophic factors (NTs) have been implicated in the control of adult neurogenesis. They serve to critical roles in the survival and differentiation of neurons during development (Bath and Lee 2010). NT mRNAs are translated into larger precursors named pro-NTs, which are then processed into mature NTs by enzymatic cleavage (Teng and Hempstead 2004; Saragovi et al. 2019). Many neurogenesis regulatory genes are not only transcribed but also translated into blood cells (https://www.proteinatlas.org). Transcriptional induction or gene repression is an important indicator of the severity of tissue pathological changes (Koval et al. 2018; Degen et al. 2020; Zherebiatiev and Kamyshnyi 2018). Our study is aimed to analyze the transcriptional activity of neurogenesis regulatory genes in peripheral blood cells in patients with the thyroid gland diseases, which can be a truly noninvasive biomarker of adult neurogenesis. Identification of hippocampal neurogenesis-specific biomarkers in blood can be used as a prognostic marker for the risk of developing neurological and psychological complications comorbid with thyroid pathology.

We used PCR arrays for evaluation of gene expression data to understand the effect of thyroid hormones and serum autoantibodies, such as an antithyroglobulin antibody (anti-Tg) and anti-thyroid peroxidase antibody (anti-TPO), on the expression of mRNA neurogenesis-regulated genes in patients with primary hypothyroidism, as a result of AIT and postoperative hypothyroidism, and patients with AIT rising serum autoantibodies, such as anti-Tg and anti-TPO.

\section{Subjects and methods}

Subjects. 153 patients with thyroid pathology were enrolled in the study. They were divided into 3 groups: group 1 included 16 patients with postoperative hypothyroidism; group 2 included 65 patients with hypothyroidism resulting from AIT, and group 3 included 72 patients with AIT and elevated serum anti-Tg and anti-TPO antibodies. The control group included 25 healthy individuals, which were recruited randomly without matching for age or sex. The clinical characteristics of the subjects are shown in Table 1.

The ethical principles contained in the Declaration of Human Rights adopted in Helsinki, in 1975, and revised in 2008, were fully respected in our study. The subjects enrolled, voluntarily participated in this study and completed and signed written informed consent. The protocol of the study was approved by the local ethics committees of HSEEU "Bukovinian State Medical University" and Chernivtsi Regional Endocrinology Center.

Patients under the age of 18 or those suffering from malignancy, inflammation associated rheumatic diseases or acute/chronic infection, diabetes mellitus, cardiovascular or cerebrovascular diseases, chronic hepatic or renal diseases, as well as pregnant women, and those using any drugs that could interfere with thyroid function, were excluded from the study.

Clinical characteristics. Hypothyroidism was diagnosed following the recommendations of the American Association of Clinical Endocrinologists 2012. The diagnosis of AIT was based on the detected circulating antibodies to thyroid antigens (anti-TPO and anti-Tg) and reduced echogenicity on thyroid sonogram in a patient with relevant clinical features (Garber et al. 2012). 
Table 1

Clinical characteristics of the subjects.

\begin{tabular}{lcccc}
\hline & $\begin{array}{c}\text { Control group } \\
(\mathbf{n = 2 5})\end{array}$ & $\begin{array}{c}\text { Patients with postoperative } \\
\text { hypothyroidism (Group 1) } \\
(\mathbf{n = 1 6})\end{array}$ & $\begin{array}{c}\text { Patients with } \\
\text { hypothyroidism as a result } \\
\text { of AIT (Group 2) } \\
(\mathbf{n = 6 5})\end{array}$ & $\begin{array}{c}\text { Patients with AIT with rising } \\
\text { serum anti-Tg and anti-TPO } \\
\text { autoantibodies (Group 3) } \\
(\mathbf{n}=\mathbf{7 2})\end{array}$ \\
\hline The age (years) & $46.08 \pm 14.58$ & $47.30 \pm 12.27$ & $46.72 \pm 15.49$ & $45.02 \pm 13.65$ \\
$\mathrm{fT} 4(\mathrm{pmol} / \mathrm{L})$ & $8.91 \pm 0.97$ & $3.44 \pm 0.31$ & $4.13 \pm 0.52$ & $8.51 \pm 0.82$ \\
$\mathrm{TSH}(\mathrm{mIU} / \mathrm{mL})$ & $2.67 \pm 0.52$ & $8.61 \pm 0.84$ & $7.09 \pm 0.50$ & $2.38 \pm 0.62$ \\
\hline anti-TPO $(\mathrm{IU} / \mathrm{mL})$ & $34.04 \pm 3.70$ & $36.13 \pm 2.78$ & $380.62 \pm 73.42$ & $330.36 \pm 50.23$ \\
\hline anti-Tg $(\mathrm{IU} / \mathrm{mL})$ & $15.32 \pm 1.97$ & $15.50 \pm 1.90$ & $32.97 \pm 4.27$ & $36.38 \pm 7.70$ \\
\hline $\begin{array}{l}\text { Current dose of } \\
\text { L-thyroxine }(\mu \mathrm{g} / \text { day) }\end{array}$ & None & $110.95 \pm 5.25$ & $88.46 \pm 1.55$ & None \\
\hline
\end{tabular}

Data are expressed as mean \pm standard deviation. Abbreviations: AIT - autoimmune thyroiditis; anti-Tg - anti-thyroglobulin antibody; anti-TPO - anti-thyroid peroxidase antibody; fT4 - free thyroxine; TSH - thyroid-stimulating hormone.

Table 2

Neurogenesis pathway-focused genes.

\begin{tabular}{llll}
\hline Unigene & Refseq & Symbol & Description \\
\hline Hs.632404 & NM_001136215 & ARTN & Artemin \\
Hs.129966 & NM_001842 & CNTFR & Ciliary neurotrophic factor receptor \\
Hs.284244 & NM_002006 & FGF2 & Fibroblast growth factor 2 (basic) \\
Hs.58042 & NM_001496 & GFRA3 & GDNF family receptor alpha 3 \\
Hs.73133 & NM_005954 & MT3 & Metallothionein 3 \\
Hs.657172 & NM_006157 & NELL1 & NEL-like 1 (chicken) \\
Hs.415768 & NM_002507 & NGFR & Nerve growth factor receptor \\
Hs.453951 & NM_013957 & NRG1 & Neuregulin 1 \\
Hs.99171 & NM_002527 & NTF3 & Neurotrophin 3 \\
Hs.406293 & NM_002529 & NTRK1 & Neurotrophic tyrosine kinase, receptor, type 1 \\
\hline Hs.494312 & NM_006180 & NTRK2 & Neurotrophic tyrosine kinase, receptor, type 2 \\
Hs.248159 & NM_004158 & PSPN & Persephin \\
Hs.518123 & NM_006070 & TFG & TRK-fused gene \\
\hline
\end{tabular}

Blood specimens were collected between 8:00 and 10:00 a.m. after an overnight fasting. Free thyroxine (fT4) (normal range 6.0-13.0 pmol/L for males and 7.0-13.5 pmol/L for females), thyroid-stimulating hormone (TSH) (normal range 0.3-4.0 $\mathrm{mIU} / \mathrm{mL}$ ), anti-TPO (normal range $0-30 \mathrm{IU} / \mathrm{mL}$ ) and anti-Tg (normal range 0-65 IU/mL) antibodies levels were determined in every individual using STAT FAX303/ Plus analyzer (Awareness Technology Inc, USA).

Experimental procedures. We used a pathwayspecific PCR array (Neurotrophins and Receptors $\mathrm{RT}^{2}$ Profiler PCR Array, QIAGEN, Germany) to identify and verify neurogenesis pathway-focused genes expression in randomly selected 12 individuals from each group using real-time PCR due to the procedure described below. A list of neurogenesis pathwayfocused genes selected for this research is given in Table 2.

RNA isolation. Total RNA was isolated from white blood cells using NucleoZOL (Macherey-Nagel, Germany) according to the manufacturer's instructions. NucleoZOL is designed for the isolation of total RNA (small and large RNA) in single or separate fractions from a variety of sample materials, such as cells, tissue, and liquids of human or animal origin. White blood cells were lysed and homogenized in NucleoZOL reagent based on guanidinium thiocyanate and phenol.

cDNA synthesis. The RNA quality was determined and reverse transcribed. The concentration and 
quality of the isolated total RNA were determined on a NanoDrop spectrophotometer (Thermo Scientific ${ }^{\mathrm{TM}}$, USA). For the reverse transcription procedure with a cDNA conversion $\mathrm{RT}^{2}$ First Strand Kit (QIAGEN, Germany, Cat. no. 330401), RNA samples with the following parameters were selected: ratio A260/A280 within the range of 1.8-2.2.

The RT2 HT First Strand Kit procedure comprises 2 steps: elimination of genomic DNA contamination, and reverse transcription, which enable fast and easy

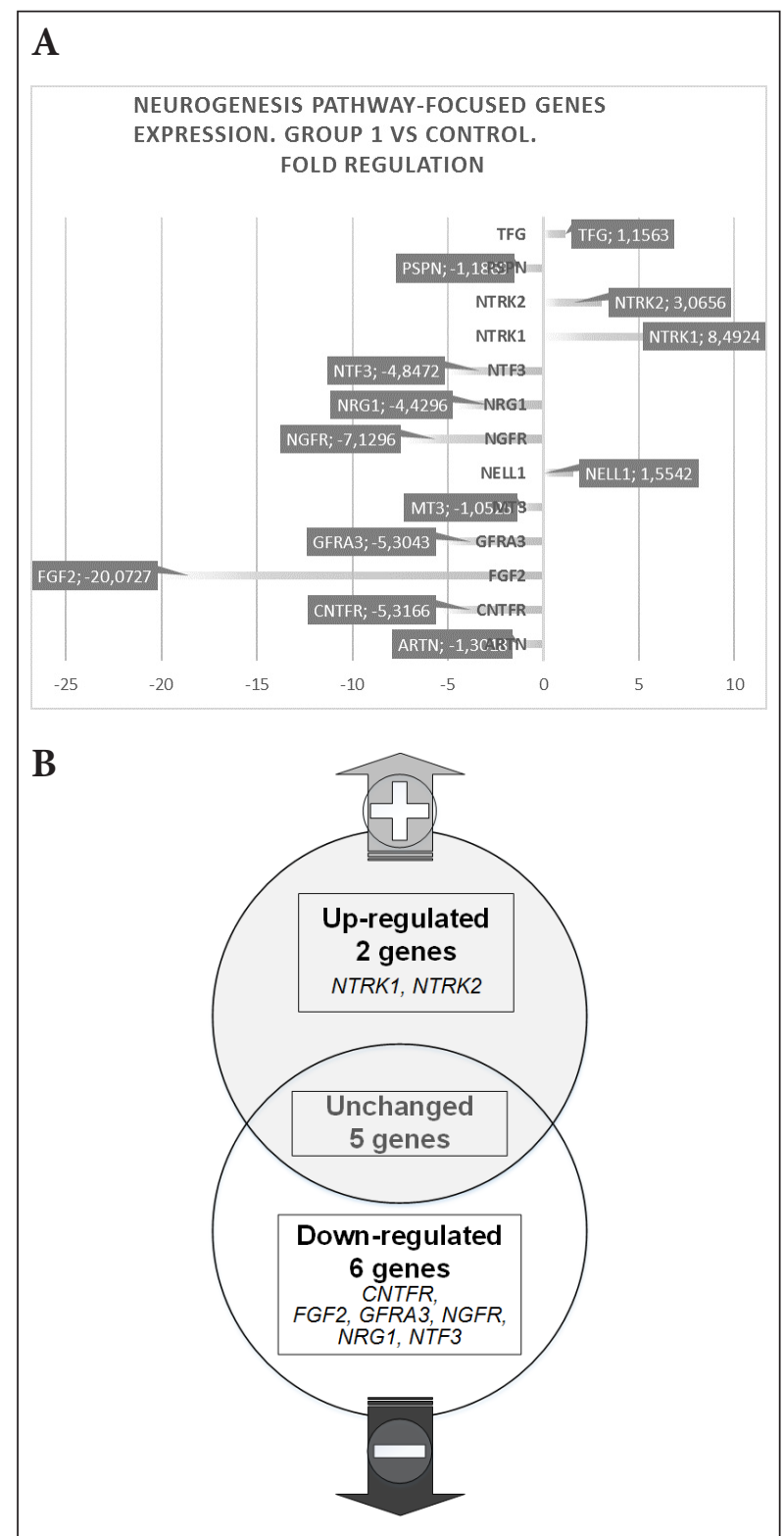

Figure 1. Differential expression of mRNA neurogenesis pathway-focused gene (Group 1 compared to the control group) (A). Venn diagram shows up- and down-regulated genes (B). handling of 96 RNA samples simultaneously. After genomic DNA elimination, the RNA sample undergoes reverse transcription with an RT master mix, as well as random hexamers and oligo-dT prime reverse transcription to capture more difficult-todetect genes.

PCR array. The CDNA was then used with RTI Profiler PCR Array (QIAGEN, Cat. no. PAHS031Z) in combination with RTI SYBR ${ }^{\circledR}$ Green $\mathrm{qPCR}$ Mastermix (QIAGEN, Cat. no. 330504), following the complete RT2 Profiler PCR Array procedure (www.qiagen.com). Samples were assigned to control and study groups. Each array contained 5 separate housekeeping genes - ACTB (Actin, beta), B2M (Beta-2-microglobulin), GAPDH (Glyceraldehyde-3phosphate dehydrogenase), HPRT1 (Hypoxanthine phosphoribosyltransferase 1), RPLP0 (Ribosomal protein, large, $\mathrm{P} 0$ ) that were used for normalization of the sample data. CT values were normalized based on an automatic selection from the full panel of reference genes. Any Ct value $>35$ was considered to be a negative call. The RT2 Profiler PCR Array data analysis software calculates the fold change based on the widely used and agreed upon the $\Delta \Delta \mathrm{Ct}$ method. The data analysis web portal calculates fold change/regulation using the delta-delta CT method, in which delta $\mathrm{CT}$ is calculated between the gene of interest (GOI) and an average of reference genes (HKG), followed by delta-delta CT calculations (delta CT (Test Group)delta CT (Control Group)). Fold Change is then calculated using a $2^{\wedge}$ (-delta-delta CT) formula. This data analysis report was exported from the QIAGEN web portal at GeneGlobe. The software allows defining the best reference genes for normalization.

Statistical analysis of PCR array data. The RT2 Profiler PCR Array Data Analysis software does not perform any statistical analysis beyond the calculation of p-values using a Student's t-test (two-tail distribution and equal variances between the two samples) based on the triplicate $2^{\wedge}(-\Delta \mathrm{CT})$ values for each gene in the experimental group compared to the control group. The Microarray Quality Control (MAQC) published results indicate that a ranked list of genes based on fold-change and associated p-value calculation was sufficient to demonstrate reproducible results across multiple microarrays and PCR Arrays, including the RT2 Profiler PCR Arrays.

\section{Results}

Using the Pathway-Focused PCR Array Profiling (Neurotrophins and Receptors $\mathrm{RT}^{2}$ Profiler PCR Array) we examined the Neurogenesis pathway- 
focused genes expression of patients with primary hypothyroidism as a result of AIT and postoperative hypothyroidism and patients with AIT with rising serum autoantibodies, such as anti-Tg and anti-TPO.

The results from RT2 Profiler Neurogenesis pathway-focused genes expression analysis indicated that in Group 1, which include patients with postoperative hypothyroidism the expression of NTRK1 and NTRK2, were increased by 8.5 and 3.06 times correspondingly, whereas the expression of CNTFR (5.3-fold), FGF2 (20.1-fold), was decreased (Figure 1). Reductions in GFRA3 (5.3-fold), NGFR (7.1-fold), NRG1 (4.4-fold), NTF3 (4.8-fold) mRNAs were also found in Group 1 (Figure 1).

In patients with hypothyroidism, as a result of AIT (Group 2), the expression of neurogenesis pathwayfocused genes changed as follows: the increase in the expressions of CNTFR (8.5-fold), NTRK1 (4.6-fold), and NTRK2 (3.4-fold) were observed. In contrast, the expressions of FGF2 (20.8-fold), and NGFR (5.1-fold) were decreased (Figure 2). As it is shown in Table 3, reductions in NRG1 (10.8-fold), NTF3 (6.1-fold) mRNAs were also found in Group 2.

We noted that in Group 3, which includes patients with AIT with rising serum anti-Tg and anti-TPO autoantibodies, the mRNA level of FGF2 (6.2-fold) was significantly increased (Figure 3). Reductions in GFRA3 (6.4-fold), NGFR (17.4-fold), NRG1 (6.9-fold), NTF3 (10.5-fold) mRNAs were found in Group 3. The expression of NTRK1 (2.7-fold), and NTRK2 (3.4fold) were markedly decreased in Group 3 (Figure 3).

Besides, we found that ARTN, PSPN, TFG, MT3, and NELL1 did not revealed any change in their expression in any group of patients.

Within our research of neurogenesis pathwayfocused genes expression, we built gene networks using GeneMANIA (http://genemania.org) that helped to determine how the candidate genes interact with other genes and generated hypotheses about the gene function, analyzing gene lists, and prioritizing genes for functional assays. As can be seen in Figure 4, within the gene network that controls the interaction and functional linkages of neurogenesis regulators, the closest functional linkages were observed between genes NTRK2, NTRK1, NGFR, MT3, NTF3, and FGF2. These functional relationships relate to several common signaling pathways - neurotrophin signaling pathway, regulation of cell morphogenesis, behavior, regulation of the development of the nervous system, regulation of neurogenesis, regulation of axonogenesis, and the central nervous system neuron development.

\section{Discussion}

Many factors like hormones, exercise, central nervous system injuries, chronic stress learning, and enriched environment modulate hippocampal neurogenesis (Cooke et al. 2014). Neurotrophic factors play a crucial role in the development, survival, differentiation, and maintenance of neurons system and adult physiology (Anders et al. 2001; Enomoto et al. 2001). Adult neurogenesis is strongly related to high sensi-

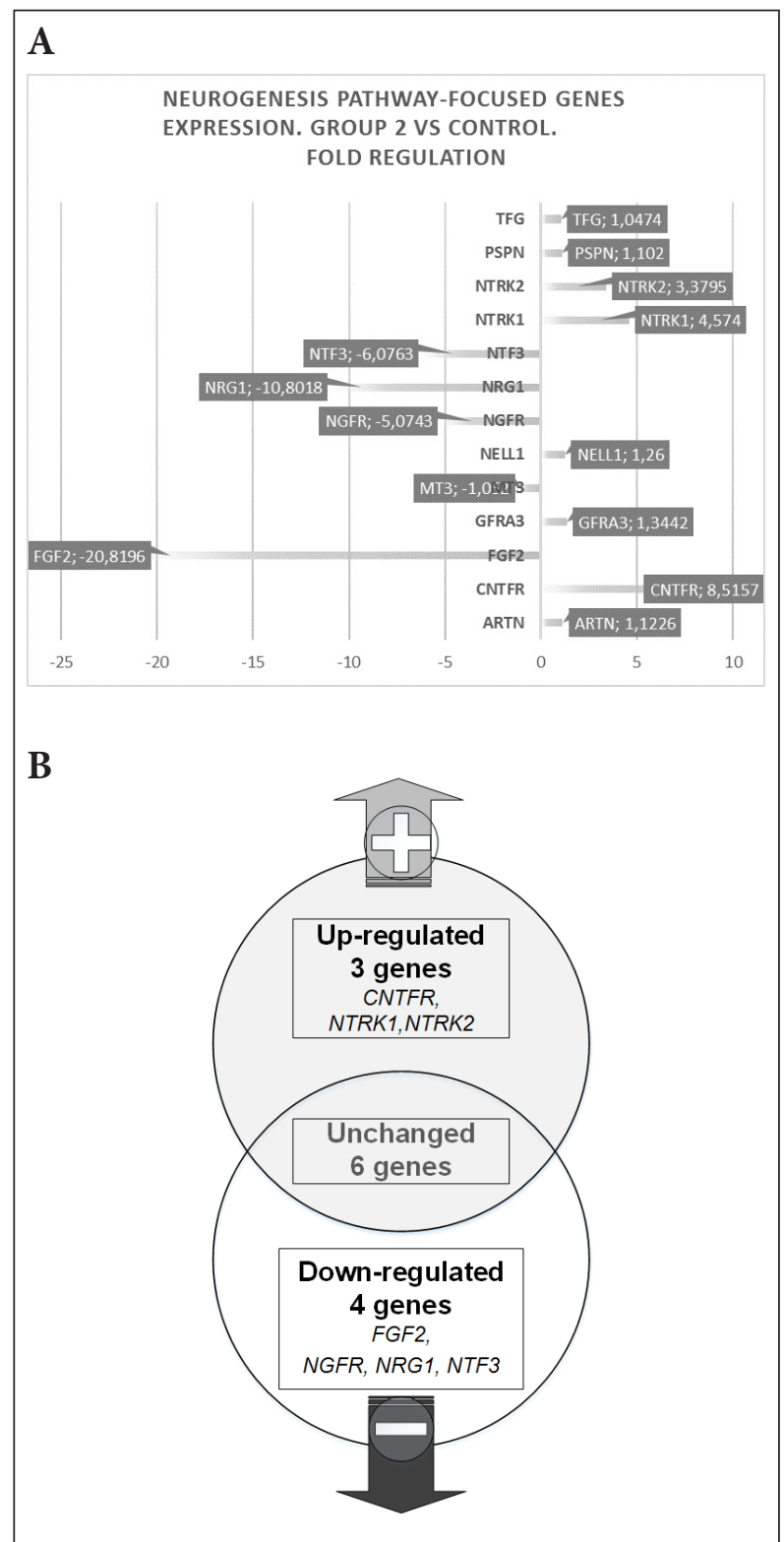

Figure 2. Differential expression of mRNA neurogenesis pathway-focused gene (Group 2 compared to the control group) (A). Venn diagram shows up- and down-regulated genes (B). 


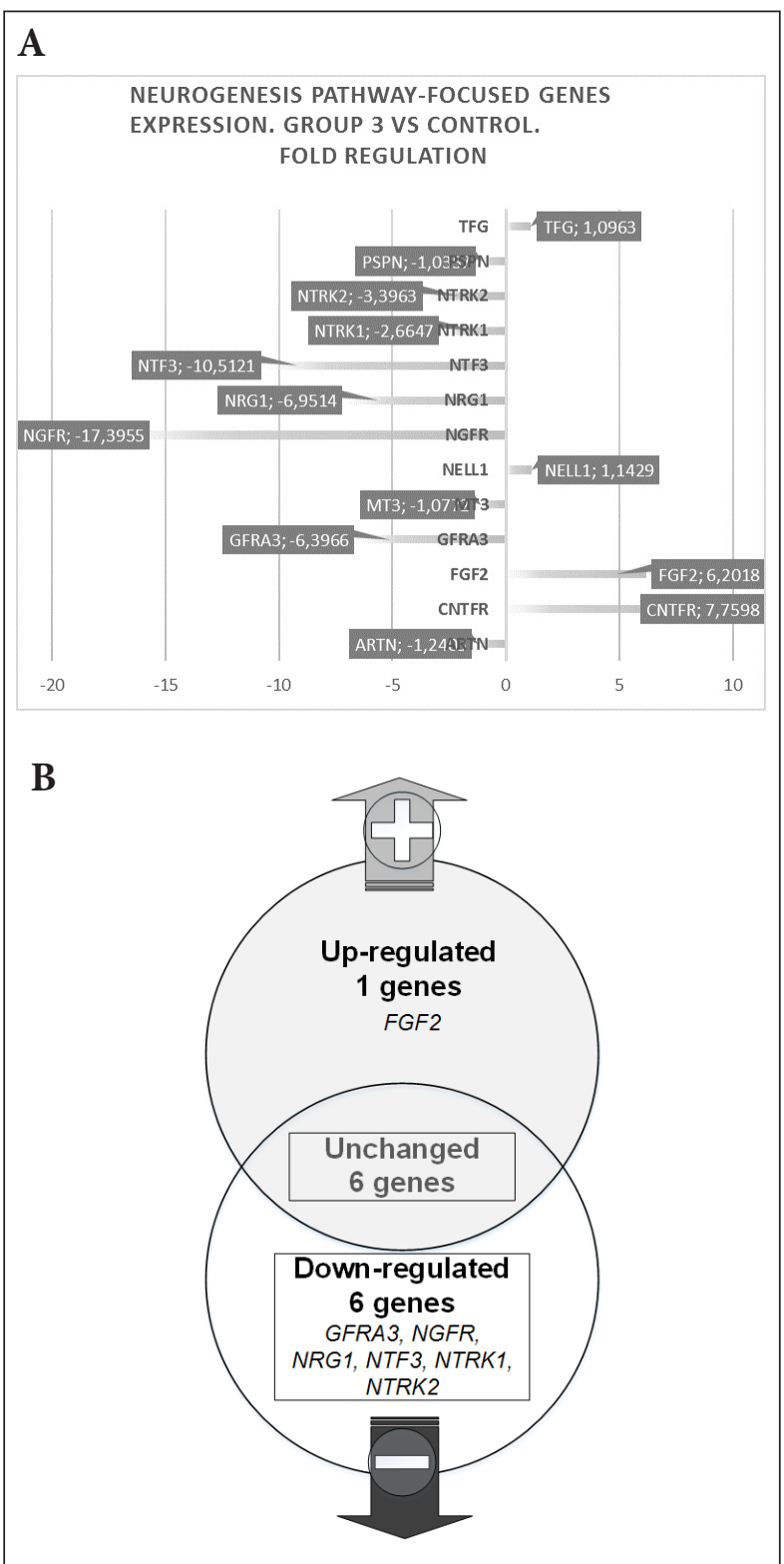

Figure 3. Differential expression of mRNA neurogenesis pathway-focused gene (Group 3 compared to the control group) (A). Venn diagram shows up- and down-regulated genes (B).

tivity to hormones, neurotransmitters, and growth factors that are present in the neurogenic niche (Mahmoud et al. 2016). It has been found that the thyroid hormone exerts profound effects on neurogenesis (Kapoor et al. 2015). These investigations have studied the direct influence of thyroid hormone on neuronal progenitors in vitro (Kapoor et al. 2012), and, what is more, the consequences of disturbing the levels of circulating thyroid hormone in vivo applying pharmacological and surgical approaches (Montero-Pedrazuela et al. 2006). In recent studies,
Table 3

Differential expression of mRNA Neurogenesis pathwayfocused genes in patients with different thyroid pathology.

\begin{tabular}{lccc}
\hline \multirow{2}{*}{ Symbol } & \multicolumn{3}{c}{ Up-Down Regulation (comparing to control group) } \\
\cline { 2 - 4 } & Group 1 & Group 2 & Group 3 \\
\cline { 2 - 4 } & Fold Regulation & Fold Regulation & Fold Regulation \\
\hline ARTN & $1.3(\mathrm{p}=0.11)$ & $1.1(\mathrm{p}=0.57)$ & $1.2(\mathrm{p}=0.07)$ \\
CNTFR & $-5.3(\mathrm{p}=0.001)$ & $8.5(\mathrm{p}=0.03)$ & $7.7(\mathrm{p}=0.19)$ \\
FGF2 & $-20.1(\mathrm{p}=0.0001)$ & $-20.8(\mathrm{p}=0.0002)$ & $6.2(\mathrm{p}=0.02)$ \\
GFRA3 & $-5.3(\mathrm{p}=0.005)$ & $1.3(\mathrm{p}=0.3)$ & $-6.4(\mathrm{p}=0.0005)$ \\
MT3 & $1.05(\mathrm{p}=0.2)$ & $1.05(\mathrm{p}=0.4)$ & $1.08(\mathrm{p}=0.06)$ \\
NELL1 & $1.5(\mathrm{p}=0.2)$ & $1.26(\mathrm{p}=0.09)$ & $1.1(\mathrm{p}=0.56)$ \\
NGFR & $-7.13(\mathrm{p}=0.008)$ & $-5.07(\mathrm{p}=0.015)$ & $-17.4(\mathrm{p}=0.006)$ \\
NRG1 & $-4.43(\mathrm{p}=0.0007)$ & $-10.8(\mathrm{p}=0.0002)$ & $-6.9(\mathrm{p}=0.002)$ \\
NTF3 & $-4.8(\mathrm{p}=0.0005)$ & $-6.07(\mathrm{p}=0.0004)$ & $-10.5(\mathrm{p}=0.00002)$ \\
NTRK1 & $8.5(\mathrm{p}=0.006)$ & $4.6(\mathrm{p}=0.001)$ & $-2.7(\mathrm{p}=0.015)$ \\
NTRK2 & $3.06(\mathrm{p}=0.014)$ & $3.4(\mathrm{p}=0.005)$ & $-3.4(\mathrm{p}=0.002)$ \\
PSPN & $1.2(\mathrm{p}=0.46)$ & $1.1(\mathrm{p}=0.38)$ & $1.03(\mathrm{p}=0.59)$ \\
TFG & $1.2(\mathrm{p}=0.11)$ & $1.05(\mathrm{p}=0.67)$ & $1.09(\mathrm{p}=0.37)$ \\
\hline
\end{tabular}

The $p$-values are calculated based on a Student's t-test of the replicate $2^{\wedge}(-$ Delta CT) values for each gene in the control group and patients groups.

the most of the use of TR isoform-specific mutant mouse lines was used to examine the effects on adult neurogenesis (Kapoor et al. 2011; Lopez-Juarez et al. 2012). Adult-onset hypothyroidism in rats considerably reduced the postmitotic survival and neuronal differentiation of hippocampal progenitors having no effects on their proliferation (Ambrogini et al. 2005). Such reduction in progenitor survival seemed to be mediated via increased apoptotic cell death. The declines in progenitor survival, as well as neuronal differentiation, were have normalized in hypothyroid animals by the recovery of euthyroid status through thyroid hormone replacement therapy (Desouza et al. 2005). The investigation in thyroidectomized rats has revealed a reduction in progenitor proliferation in the hippocampus. (Montero-Pedrazuela et al. 2006). Although in vivo studies have firmly indicated the essential effects of thyroid hormone on adult hippocampal neurogenesis (Kapoor et al. 2015), thus far, these studies did not clearly provide a distinction whether the neurogenic effects of thyroid hormone are mediated directly on progenitors or via an effect on a neurogenic niche. At the same time, there is practically no evidence on the effect of changes at the level of thyroid hormones on the expression of neurogenesis regulators in the peripheral blood in patients. 


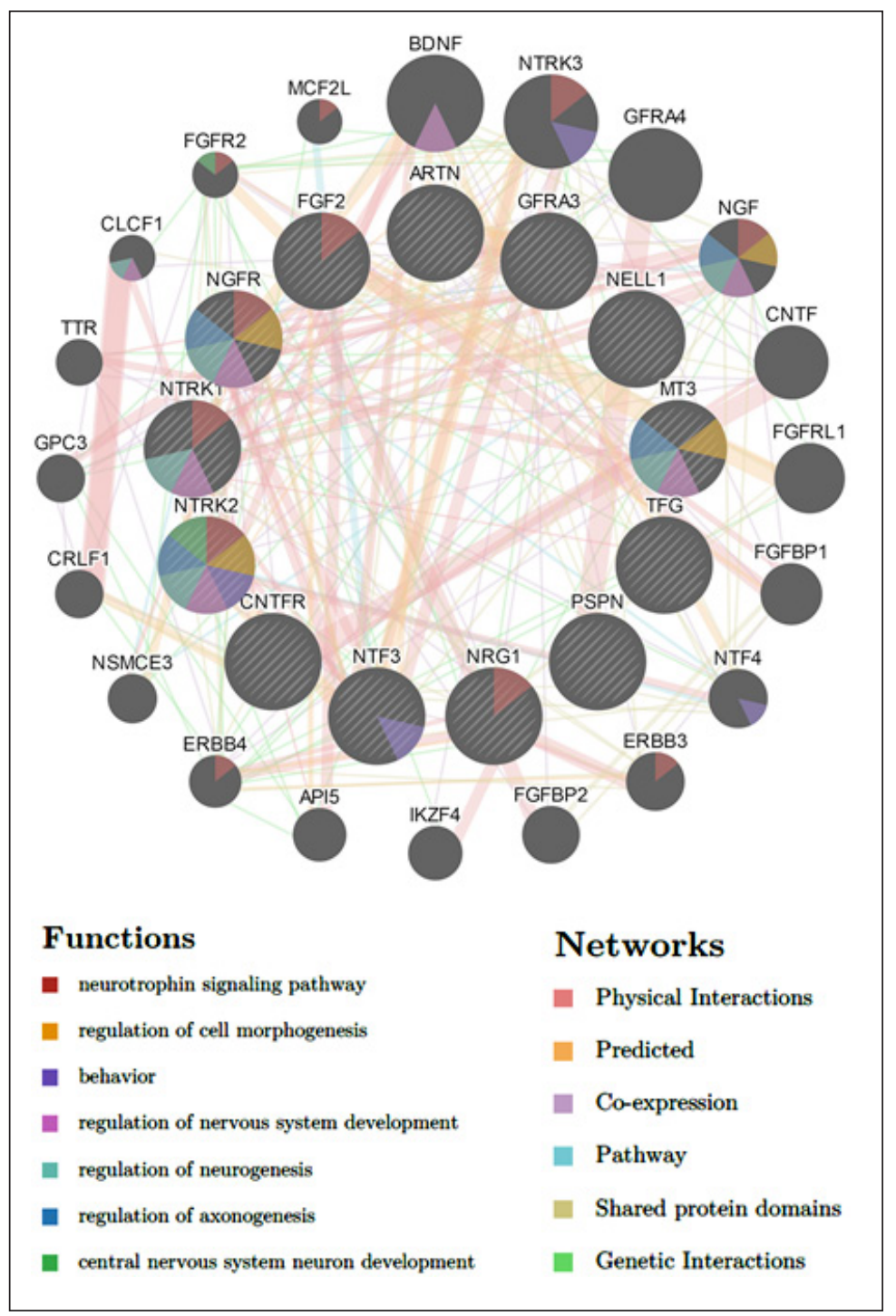

Figure 4. Gene interaction network and functional linkages of genes regulating neurogenesis.

Previously, we have shown changes in transcriptional activity under conditions of thyroid pathology of such neurotrophic factors as BDNF, CBLN1, CNTF, GDNF, and MEF2C, which are important regulators not only of synaptogenesis but also of neurogenesis (Bilous et al. 2020a). There are also several regulators of neurogenesis, the level of which may depend on the functional activity of the thyroid gland.

ARTN is a member of the glial cell line-derived neurotrophic factor family ligands. ARTN plasma levels are reduced in patients with major depressive disorder (Pallanti et al. 2014). Using quantitative real/ time PCR method in peripheral blood cells, reduced expression levels of GDNF, ARTN, and NT-3 mRNAs have been found in patients with major depressive disorder in a current depressive state. Changes in the expression levels of GDNF, ARTN, and NT-3 mRNAs have been interpreted as state-dependent and associated with the pathophysiology of major depression (Otsuki et al. 2008). We found that ARTN did not change significantly its expression in any group of patients.

However, ARTN exerts its influence on intracellular signaling pathways via binding to the receptor complex of GDNF family receptor alpha 3 (GFRA3) and ret (Baloh et al. 1998). In our study, we noted that GFRA3 was downregulated in Groups 1 and 3 more than by 5 times. So, thyroid dysfunction can influ- 
ence the ARNT through suppression of gene expression of GFRA3, a highly selective receptor for ARTN.

In their current studies, the authors have reported deficits in the hippocampal-dependent spatial learning and memory in adult rats with TH deficiency (Artis et al. 2012), which are followed by impairments in LTP (long-term potentiation) and neurotrophic factors expression in the hippocampus (Husson et al. 2004).

FGF2 plays an important role in the neurodevelopment and maintenance of the central nervous system (Molteni et al. 2001). In SCZ, data from Hashimoto et al. (2003) have shown increased serum FGF2 protein levels in medicated SCZ patients. Patients suffering from the major depressive disorder have deregulated FGF transcript levels that are restored by serotonin reuptake inhibitors (Evans et al. 2004). Thyroid hormone dysfunction is associated with affective disorders, as well as enhanced susceptibility to depressive symptomatology in hypothyroid patients and increased anxiety reported in subjects with hyperthyroidism (Dayan and Panicker 2013). Some studies have shown that high FGF2 concentrations or a brief thyroid hormone treatment elicit oligodendrocytes formation at the expense of neurons (Williams et al. 1997). In the same way, FGF2 and T3 show a preference for an oligodendrocyte over a neuronal fate in neonatal NSCs grown in spheres (Ben Hur et al. 1998). In our investigation, we noted that there was a significant decrease in the expression of FGF2 in Groups land 2 by more than 20 times. On the other hand, in Group 3 the expression of FGF2 was increased. So, we can assume that in the case of the lower level of thyroid hormones a result of AIT and postoperative hypothyroidism the expression of FGF2, will be suppressed.

CNTF is almost exclusively expressed in the nervous system, is produced by astrocytes in the brain in the SVZ (Dallner et al. 2002) to promote neurogenesis (Yang et al. 2008), possibly through the upregulation of FGF2 (Kang et al. 2013), which stimulates progenitor production (Kuhn et al. 1997). Its effect is realized through CNTFR. In our study, the expression of CNTFR was downregulated in the group of patients with postoperative hypothyroidism.

NGF plays an important role in the processes of neuronal survival, ischemic tolerance of the brain and it is involved in the mechanism, by which neurons can be protected from cell death (Shigeno et al. 1991). Several studies have also shown that the thyroid hormone regulates NGF expression (Lindholm et al. 1993). Thyroxine given to adult rats and mice elevates NGF levels in the cortex, hippocampus, and cerebellum (Giordano et al. 1992). On the contrary, hypothyroidism in adult rats decreases NGF mRNA levels in the cortex, hippocampus, and cerebellum (Alverez-Dolado et al. 1994).

The results of our study indicated that NGFR significantly decreased their expression in all groups of the patients. What is more, the lowest expression was in patients with AIT with rising serum autoantibodies, such as anti-Tg and anti-TPO and normal levels of thyroid hormones. NRG1 gene polymorphism has been assessed as a risk factor for schizophrenia development (He et al. 2016). Additionally, some studies have measured peripheral levels and gene expression of NRG1, which was decreased in schizophrenia patients (Wang et al. 2015). Correlation of executive functions deficits with downregulation of NRG1 types has shown the important role of NRG1 in the orchestration of a number of executive functions including response inhibition, vigilance, and working memory in ASD patients (Abbasy et al. 2018). Our research demonstrated that the expression of NRG1 was significantly decreased in each group of patients compared with the control group.

NTF3, a member of the NT family, has emerged as a key mediator of neuronal development which promotes the survival/differentiation cascade during neuronal differentiation (Lin et al. 2018). The expression of NTF3 is regulated by thyroid hormones (Lindholm et al. 1993). T3 induces NTF3 mRNA expression and neuronal development in the neonatal cerebellum (Lindholm et al. 1993). Thyroxine, which is administered to adult rats and mice, elevates NTF3 levels in the cortex, hippocampus, and cerebellum (Giordano et al. 1992). NT-3 mRNA levels in the cerebellum are reduced by hypothyroidism in neonates (Lindholm et al. 1993).

We noted that NTF3 was downregulated in all groups of patients. Moreover, the lowest expression was in Group 3. So, NTF3 demonstrated at least a 10 -fold difference in gene expression compared with the controls.

The mRNA expression of neurotrophins (BDNF, NT3, and NT4) and their receptors (TrkA [NTRK1], TrkB [NTRK2] and p75NTR) in the whole blood were determined by quantitative real-time polymerase chain reaction (qRT-PCR) in patients with ASD (Segura et al. 2015). TrkB signalings triggered by NTs play a central role in cell proliferation, survival, and differentiation, as well as synaptic plasticity, and neurotransmitter release (Barbacid 1995; Skaper 2008). Another study has suggested the involvement of an NTRK2 tag SNP in emotional processing andindependently-in brain white-matter integrity in 
healthy young subjects (Spalek et al. 2016). In our study, we found, that in Groups 1 and 2 NTRK1 and NTRK2 were upregulated. Patients with AIT with rising serum autoantibodies had significantly lower expression of NTRK1 and NTRK2. We can presume that a high level of autoantibodies such as anti-Tg and anti-TPO, can suppress the expression of NTRK1 and NTRK2 and there is a primary brain-specific mechanism independent from thyroid hormone level. Moreover, there is little evidence about the specific cellular mechanism that can be altered by the dysfunction resulted from the decrease in thyroid hormone levels. For that reason, it is necessary to develop efficient means against the consequences of hypothyroidism prevent to some brain pathologies in adulthood.

\section{Conclusions}

In summary, the results from neurogenesis pathway-focused gene expression analysis showed that GFRA3, NGFR, NRG1, NTF3, NTRK1, and NTRK2 significantly decreased their expression in Group 3, which include patients with AIT rising serum autoantibodies, such as anti-Tg and antiTPO. The patients with primary hypothyroidism, as a result of AIT and postoperative hypothyroidism, had significantly lower expression of CBLN1, FGF2, NGFR, NRG1, and NTF3. The expression of CNTFR was decreased only in the group of patients with postoperative hypothyroidism. ARTN, PSPN, TFG, MT3, and NELL1 did not change their expression in all groups of patients.

It is important to estimate how much hypothyroidism effects the neurogenesis. Thyroid hormones interact with a broad range of neurotransmitter systems and are thought to be involved in the regulation of different neurological processes including post-receptor and signal-transducing processes, as well as the gene regulatory mechanisms. Since, it remains unclear that what is the role of serum autoantibodies, such as anti-Tg and anti-TPO, in patients with AIT in the regulation of adult neurogenesis and mechanisms of brain injury responsible for the psychological and neurological impairments in the context of euthyroid AIT, further studies are required.

\section{References}

Abbasy S, Shahraki F, Haghighatfard A, Qazvini MG, Rafiei ST, Noshadirad E, Farhadi M, Rezvani Asl H, Shiryazdi AA, Ghamari R, Tabrizi Z, Mehrfard R, Esmaili Kakroudi F, Azarnoosh M, Younesi F, Parsamehr N, Garaei N, Abyari S, Salehi M, Gholami M, Zolfaghari P, Bagheri SM, Pourmehrabi M, Rastegarimogaddam E, Nobakht E, Nobakht E, Partovi R. Neuregulin1 types mRNA level changes in autism spectrum disorder, and is associated with deficit in executive functions. EBioMedicine 37, 483-488, 2018.

Alverez-Dolado M, Iglesias T, Rodriguez-Pena A, Bernal J, Munoz A. Expression of neurotrophins and the trk family of neurotrophin receptors in normal and hypothyroid rat brain. Mol Brain Res 27, 249-257, 1994.

Ambrogini P, Cuppini R, Ferri P, Mancini C, Ciaroni S, Voci A, Gerdoni E, Gallo G. Thyroid hormones affect neurogenesis in the dentate gyrus of adult rat. Neuroendocrinology 81, 244-253, 2005.

Anders J, Kjar S, Ibanez CF. Molecular modeling of the extracellular domain of the RET receptor tyrosine kinase reveals multiple cadherin-like domains and a calcium binding site. J Biol Chem 276, 35808-35817, 2001.

Artis AS, Bitiktas S, Taskin E, Dolu N, Liman N, Suer C. Experimental hypothyroidism delays field excitatory postsynaptic potentials and disrupts hippo- campal long-term potentiation in the dentate gyrus of hippocampal formation and Y-maze performance in adult rats. J Neuroendocrinol 24, 422-433, 2012.

Baloh RH, Tansey MG, Lampe PA, Fahrner TJ, Enomoto H, Simburger KS, Leitner ML, Araki T, Johnson EM Jr, Milbrandt J. Artemin, a novel member of the GDNF ligand family, supports peripheral and central neurons and signals through the GFRalpha3-RET receptor complex. Neuron 21, 1291-1302, 1998.

Barbacid M. Structural and functional properties of the TRKfamily of neurotrophin receptors. Ann N Y Acad Sci 766, 442-458, 1995.

Bath KG, Lee FS. Neurotrophic factor control of adult SVZ neurogenesis. Dev Neurobiol 70, 339-349, 2010.

Ben-Hur T, Rogister B, Murray K, Rougon G, Dubois-Dalcq M. Growth and fate of PSA-NCAM+ precursors of the postnatal brain. J Neurosci 18, 5777-5788, 1998.

Bilous II, Korda MM, Krynytska IY, Kamyshnyi AM. Nerve impulse transmission pathway-focused genes expression analysis in patients with primary hypothyroidism and autoimmune thyroiditis. Endocr Regul 54, 101-110, 2020a.

Bilous I, Pavlovych L, Krynytska I, Marushchak M, Kamyshnyi A. Apoptosis and cell cycle pathway-focused genes expression analysis in patients with different forms of thyroid pathology. Open Access Maced J Med Sci 8(B), 784-792, 2020b. 
Cooke GE, Mullally S, Correia N, O’Mara SM, Gibney J. Hippocampal volume is decreased in adults with hypothyroidism. Thyroid 24, 433-440, 2014.

Costa V, Lugert S, Jagasia R. Role of adult hippocampal neurogenesis in cognition in physiology and disease: pharmacological targets and biomarkers. Handb Exp Pharmacol 228, 99-155, 2015.

Dallner C, Woods AG, Deller T, Kirsch M, Hofmann HD. CNTF and CNTF receptor alpha are constitutively expressed by astrocytes in the mouse brain. Glia 37, 374-378, 2002.

Dayan CM, Panicker V. Hypothyroidism and depression. Eur Thyroid J 2, 168-179, 2013.

Degen A, Krynytska I, Kamyshnyi A. Changes in the transcriptional activity of the entero-insular axis genes in streptozotocin-induced diabetes and after the administration of TNF- $\alpha$ non-selective blockers. Endocr Regul 54, 101-110, 2020.

Desouza LA, Ladiwala U, Daniel SM, Agashe S, Vaidya RA, Vaidya VA. Thyroid hormone regulates hippocampal neurogenesis in the adult rat brain. Mol Cell Neurosci 29, 414-426. 2005.

Enomoto H, Crawford PA, Gorodinsky A, Heuckeroth RO, Johnson EMJ, Milbrandt J. RET signaling is essential for migration, axonal growth and axon guidance of developing sympathetic neurons. Development 128 , 3963-3974, 2001.

Evans SJ, Choudary PV, Neal CR, Li JZ, Vawter MP, Tomita H, Lopez JF, Thompson RC, Meng F, Stead JD, Walsh DM, Myers RM, Bunney WE, Watson SJ, Jones EG, Akil H. Dysregulation of the fibroblast growth factor system in major depression. Proc Natl Acad Sci U S A 101, 15506-15511, 2004.

Feldman AZ, Shrestha RT, Hennessey JV. Neuropsychiatric manifestations of thyroid disease. Endocrinol Metab Clin North Am 42, 453-476, 2013.

Garber JR, Cobin RH, Gharib H, Hennessey JV, Klein I, Mechanick JI, Pessah-Pollack R, Singer PA, Woeber KA; American Association of Clinical Endocrinologists and American Thyroid Association Taskforce on Hypothyroidism in Adults. Clinical practice guidelines for hypothyroidism in adults: cosponsored by the American Association of Clinical Endocrinologists and the American Thyroid Association. Endocr Pract $18,988-1028,2012$.

Giordano T, Pan J, Casuto D, Watanabe S, Arneric S. Thyroid hormone regulation of NGF, NT-3 and BDNF RNA in the adult rat brain. Mol Brain Res 16, 239-245. 1992.

Hashimoto K, Shimizu E, Komatsu N, Nakazato M, Okamura N, Watanabe H, Kumakiri C, Shinoda N, Okada S, Takei N, Iyo M. Increased levels of serum basic fibroblast growth factor in schizophrenia. Psychiatry Res 120, 211-218, 2003.

He BS, Zhang LY, Pan YQ, Lin K, Zhang LL, Sun HL, Gao TY, Su TQ, Wang SK, Zhu CB. Association of the DISC1 and NRG1 genetic polymorphisms with schizophrenia in a Chinese population. Gene 590, 293-297, 2016.

Husson M, Enderlin V, Alfos S, Boucheron C, Pallet V, Higueret P. Expression of neurogranin and neuromodulin is affected in the striatum of vitamin A- deprived rats. Brain Res Mol Brain Res 123, 7-17. 2004.

Kang SS, Keasey MP, Arnold SA, Reid R, Geralds J, Hagg T. Endogenous CNTF mediates stroke-induced adult CNS neurogenesis in mice. Neurobiol Dis 49, 68-78, 2013.

Kapoor R, Ghosh H, Nordstrom K, Vennstrom B, Vaidya VA. Loss of thyroid hormone receptor beta is associated with increased progenitor proliferation and NeuroD positive cell number in the adult hippocampus. Neurosci Lett 487, 199-203. 2011.

Kapoor R, Desouza LA, Nanavaty IN, Kernie SG, Vaidya VA. Thyroid hormone accelerates the differentiation of adult hippocampal progenitors. J Neuroendocrinol 24, 1259-1271, 2012.

Kapoor R, Fanibunda SE, Desouza LA, Guha SK, Vaidya VA. Perspec- tives on thyroid hormone action in adult neurogenesis. J Neuroendocrinol 133, 599-616, 2015.

Koval HD, Chopyak VV, Kamyshnyi OM, Kurpisz MK. Transcription regulatory factor expression in T-helper cell differentiation pathway in eutopic endometrial tissue samples of women with endometriosis associated with infertility. Cent Eur J Immunol 43, 90-96, 2018.

Kuhn HG, Winkler J, Kempermann G, Thal LJ, Gage FH. Epidermal growth factor and fibroblast growth factor-2 have different effects on neural progenitors in the adult rat brain. J Neurosci 17, 5820-5829, 1997.

Lin YJ, Hsin IL, Sun HS, Lin S, Lai YL, Chen HY, Chen TY, Chen YP, Shen YT, Wu HM. NTF3 is a novel target gene of the transcription factor POU3F2 and is required for neuronal differentiation. Mol Neurobiol 55, 8403-8413, 2018.

Lindholm D, Castren E, Tsoulfas P, Kolbeck R, Berzaghi M, Leingartner A, Tessarollo L, Prada L, Thoenen H. Neurotrophin-3 induced by tri-iodothyronine in cerebellar granule cells promotes purkinje cell differentiation. J Cell Biol 122, 443-450, 1993. 
Lopez-Juarez A, Remaud S, Hassani Z, Jolivet P, Pierre Simons J, Sontag T, Yoshikawa K, Price J, Morvan-Dubois G, Demeneix BA. Thyroid hormone signaling acts as a neurogenic switch by repressing Sox 2 in the adult neural stem cell niche. Cell Stem Cell 10, 531-543, 2012.

Mahmoud R, Wainwright SR, Galea LA. Sex hormones and adult hippocampal neurogenesis: Regulation, implications, and potential mechanisms. Front Neuroendocrinol 41, 129-152, 2016.

Molteni R, Fumagalli F, Magnaghi V, Roceri M, Gennarelli M, Racagni G. Modulation of fibroblast growth factor-2 by stress and corticosteroids: from developmental events to adult brain plasticity. Brain Res Brain Res Rev 37, 249-258, 2001.

Montero-Pedrazuela A, Venero C, Lavado-Autric R, Fernandez-Lamo I, Garcia-Verdugo JM, Bernal J, Guadano-Ferraz A. Modulation of adult hippocampal neurogenesis by thyroid hormones: Implications in depressive-like behavior. Mol Psychiatry 11, 361-371. 2006.

Otsuki K, Uchida S, Watanuki T, Wakabayashi Y, Fujimoto M, Matsubara T, Funato H, Watanabe Y. Altered expression of neurotrophic factors in patients with major depression. J Psychiatr Res 42, 1145-1153, 2008.

Pallanti S, Tofani T, Zanardelli M, Di Cesare Mannelli L, Ghelardini C. BDNF and ARTEMIN are increased in drugnaive non-depressed GAD patients: preliminary data. Int J Psychiatry Clin Pract 18, 255-260, 2014.

Rovet JF. The role of thyroid hormones for brain development and cognitive function. Endocr Dev 26, 26-43, 2014.

Samuels MH. Psychiatric and cognitive manifestations of hypothyroidism. Curr Opin Endocrinol Diabetes Obes 21, 377-383, 2014.

Saragovi HU, Galan A, Levin LA. Neuroprotection: pro-survival and anti-neurotoxic mechanisms as therapeutic strategies in neurodegeneration. Front Cell Neurosci 13, 231, 2019.

Schroeder AC, Privalsky ML. Thyroid hormones, t3 and t4, in the brain. Front Endocrinol (Lausanne) 5, 40, 2014.

Segura M, Pedreno C, Obiols J, Taurines R, Pamias M, Grunblatt E, Gella A. Neurotrophin blood-based gene expression and social cognition analysis in patients with autism spectrum disorder. Neurogenetics 16, 123-131, 2015.

Shigeno T, Mima T, Takakura K, Graham DI, Kato G, Hashimoto Y, Furukawa S. Amelioration of delayed neuronal death in the hippocampus by nerve growth factor. J Neurosci 11, 2914-2919, 1991.

Siegmann EM, Muller HHO, Luecke C, Philipsen A, Kornhuber J, Gromer TW. Association of depression and anxiety disorders with autoimmune thyroiditis: a systematic review and meta-analysis. JAMA Psychiatry 75, 577-584, 2018.

Skaper SD. The biology of neurotrophins, signalling pathways, and functional peptide mimetics of neurotrophins and their receptors. CNS Neurol Disord Drug Targets 7, 46-62, 2008.

Spalek K, Coynel D, Freytag V, Hartmann F, Heck A, Milnik A, de Quervain D, Papassotiropoulos A. A common NTRK2 variant is associated with emotional arousal and brain white-matter integrity in healthy young subjects. Transl Psychiatry 6, e758, 2016.

Teng KK, Hempstead BL. Neurotrophins and their receptors: signaling trios in complex biological systems. Cell Mol Life Sci 61, 35-48, 2004.

Wang R, Wang Y, Hu R, Chen X, Song M, Wang X. Decreased plasma levels of neureglin-1 in drug naïve patients and chronic patients with schizophrenia. Neurosci Lett 606, 220-224, 2015.

Williams BP, Park JK, Alberta JA, Muhlebach SG, Hwang GY, Roberts TM, Stiles CD. A PDGF-regulated immediate early gene response initiates neuronal differentiation in ventricular zone progenitor cells. Neuron 18, 553-562, 1997.

Yang P, Arnold SA, Habas A, Hetman M, Hagg T. Ciliary neurotrophic factor mediates dopamine D2 receptor-induced CNS neurogenesis in adult mice. J Neurosci 28, 2231-2241, 2008.

Zherebiatiev A, Kamyshnyi A. Expression levels of proinflammatory cytokines and NLRP3 inflammasome in an experimental model of oxazolone-induced colitis. Iran J Allergy Asthma Immunol 15, 39-45, 2016. 